\title{
Evaluation of nutritional status using anthropometric measurements and MQSGA in geriatric hemodialysis patients
}

\author{
Irem Pembegul Yigit, ${ }^{1}$ Ramazan Ulu, ${ }^{2}$ Huseyin Celiker, ${ }^{2}$ Ayhan Dogukan ${ }^{2}$ \\ ${ }^{1}$ Department of Nephrology, Malatya State Hospital, Malatya, Turkey \\ ${ }^{2}$ Department of Nephrology, Firat University Faculty of Medicine, Elazig, Turkey
}

\begin{abstract}
OBJECTIVE: Malnutrition is common among hemodialysis patients and is associated with higher rates of morbidity and mortality. The aim of this study was to evaluate nutritional status of geriatric hemodialysis patients.

METHODS: Total of 163 hemodialysis patients were initially screened, and 55 patients ( 28 males, 27 females; mean age: $72.9 \pm 8.4$ years) met the criteria for inclusion. Patients were divided into 3 groups according to modified quantitative subjective global assessment (MQSGA) scores: Group I $(n=22)$ normal nutrition, Group II $(n=20)$ mild-to-moderate malnutrition, and Group III $(n=13)$ severe malnutrition.

RESULTS: When we assessed the correlation between MQSGA nutrition score and data of malnourished patients $(n=33)$, positive significant correlation was found between age, C-reactive protein level, and malnutrition-inflammation score. Negative significant correlation was found between body mass index, bicep skinfold, tricep skinfold, mid-arm circumference, mid-arm muscle circumference, and phosphate and albumin levels.
\end{abstract}

CONCLUSION: Malnutrition is very common and increasing with aging in geriatric hemodialysis patients. MQSGA score and anthropometric measurements can be used to assess nutritional status in geriatric hemodialysis patients.

Keywords: Anthropometric measurements; geriatric; hemodialysis; malnutrition; MQSGA.

$\mathrm{I}_{\mathrm{P}}^{\mathrm{n}}$ $n$ recent years, increasing numbers of geriatric patients started dialysis because of higher prevalence of diabetes mellitus (DM), hypertension, and cardiovascular diseases. According to the 2014 registry report [1], $48 \%$ of patients starting dialysis in Turkey were $\geq 65$ years old. Due to the bio- logical, psychological and social outcomes of aging, the prevalence of malnutrition is increasing in these patients. Protein-energy wasting (PEW), a state of loss of body protein mass and energy stores, is a common syndrome among patients on maintenance hemodialysis (MHD), and a large amount of argu- 
ment shows that PEW is associated with increased morbidity and mortality in these patients [2]. The pathogenesis of PEW in MHD patients is multifactorial, including uremic milieu, metabolic acidosis, inadequate dialysis, secondary hyperparathyroidism, gastroparesis, loss of appetite, inadequate dietary calorie and protein intake, polypharmacy, hypercatabolism and comorbidities $[3,4]$. The incidence of malnutrition among elderly MHD patients may be higher than younger patients [5]. Also, depression, cognitive dysfunction, poverty, loneliness and sedentarism are additional factors take part in the pathogenesis of PEW in geriatric MHD patients. According to various nutritional assessment methods, the prevalence of PEW in the elderly MHD patients is reported in a range of $26-77 \%$ [6]. PEW and inflammation often co-exist and are associated with accelerated atherosclerosis and is called malnutrition-inflammation-atherosclerosis (MIA) syndrome. The life expectancy and quality of life decrease with the increasing incidence of the components of the MIA syndrome in MHD patients $[7,8]$. Because of this situation international guidelines recommend that nutritional status should be assessed periodically in patients on MHD.

The wide range of prevalence of PEW in MHD patients is probably explained by the lack of a gold standart to detect PEW in these patients and nutritional status is frequently ignored in many dialysis centers. Different methods are used to assess the nutritional status of MHD patients, such as Subjective Global assessment (SGA), modified quantitative subjective global assessment (MQSGA) and malnutrition-inflammation score (MIS). MQSGA was developed by Kalantar-Zadeh et al. [9], suggesting that a modified malnutrition scoring system may be superior to the SGA and an inexpensive, rapidly conducted tool used by physicians to assess PEW in MHD patients. In current literature, there is very little data about the nutritional status of geriatric $\mathrm{MHD}$ patients. Hence, in this study, we assessed the nutritional status of geriatric MHD patients in our HD units using standard techniques of assessment like anthropometric measurements and biochemical parameters and the correlation with MQSGA and MIS.

\section{MATERIALS AND METHODS}

\section{Patients}

This cross sectional study was performed at Hemodialysis Units of Firat University and Malatya State Hospital, Turkey. The study was approved by the Local Ethic Committee of Firat University and all patients gave written informed consent. All subjects underwent detailed clinical examination. Demographic information and medical history of patients were obtained at baseline by interview with patients and review of the medical records. $163 \mathrm{MDH}$ patients were initially screened and 55 patients included due to no presence of an exclusion criteria. Exclusion criteria of the study were as follows: $\mathrm{Pa}$ tients who had been receiving HD for less than 3 months, $<65$ years old, serum PTH levels $>800$ $\mathrm{pg} / \mathrm{ml}$, malignancy, infectious disease, insufficient dialysis $(\mathrm{Kt} /$ Vurea $<1.2)$, receiving parenteral nutrition, treatment with immunosuppressor drugs, unwillingness to participate to the study and unable to answer the questions due to dementia. All patients received 3 times a week about 3.5-4 h/each session on standard bicarbonate dialysis using a standart biocompatible HD membrane. Blood flow rates were $250-300 \mathrm{ml} / \mathrm{min}$ and dialysate flow rates were $500 \mathrm{ml} / \mathrm{min}$. Ultrafiltration varied according to the patients' actual weight. Patients divided into three groups according to MQSGA scores, Group I $(n=22)$ normal nutrition, Group II $(n=20)$ mildto-moderate malnutrition, and Group III $(n=13)$ severe malnutrition.

\section{Laboratory assessment}

Blood samples were taken after an overnight fast in the morning between 07.00-08.00 a.m. before the HD session. At the end of the HD session the blood pump speed was reduced to $<80 \mathrm{ml} / \mathrm{min}$ and blood samples was obtained at 2 min post-dialysis from the arterial dialysis tubing for the calculation of the adequacy of dialysis by $\mathrm{Kt} /$ Vurea. Laboratory analyses, including creatinine, total cholesterol, triglyceride, albumin, iron, total iron binding capacity (TIBC), albumin, calcium, phosphorus, alkaline phosphates (ALP), parathyroid hormone (PTH), hemoglobin $(\mathrm{Hb})$ and $\mathrm{C}$-Reactive Protein $(\mathrm{CRP})$ 
were measured by standard laboratory methods in central laboratories at the same day and by using standard automated methods. Kt/Vurea calculations of the patients were made on-line via the Hypertension Dialysis and Clinical Nephrology website (www.hdcn.com) by submitting patients' dialysis technique and test results.

\section{Modified quantitative subjective global assessment}

MQSGA involves seven components; weight change, dietary intake, gastrointestinal symptoms, functional capacity, comorbidity, signs of subcutaneous fat and muscle wasting. Each component was given a score from 1 (normal) to 5 (very severe). The MQSGA score, sum of all components, ranged from 7 (normal) to 35 (severely malnourished). Patients were categorized into three groups: normal nutrition (score of 7-10), mild-to-moderate malnutrition (score of 11-20), and severe malnutrition (score of 21-35).

\section{Malnutrition-inflammation score}

MIS is regarded as one of the comprehensive and specific scoring systems spesific for evaluation of MIA in MHD patients (10). This questionnaire includes 10 parameters and evaluated by giving scores between 0 (normal) and 3 (severely malnourished). The first three sections are similar to SGA items, but the fourth section includes serum albumin and TIBC. The MIS has total score ranging from 0 (normal) to 30 (severely malnourished and inflammation status).

\section{Anthropometric measurements}

Height, body weight and anthropometric measurements were performed within 10-30 minutes after HD treatment by the nephrologist. Biceps skinfold (BSF) and triceps skinfold (TSF) thicknesses were measured with a conventional skinfold caliper using standard techniques. Mid-arm circumference (MAC) was measured with a plastic tape. Mid-arm muscle circumference (MAMC) was calculated from the formula: MAMC $=$ MAC $-(3.1415 x$ TSF $)$. All anthropometric measurements were performed non-access arm. Body mass index (BMI) was calculated as the ratio of post-HD body weight in kilogram and the square of the height in meters $\left(\mathrm{kg} / \mathrm{m}^{2}\right)$.

\section{Statistical analysis}

Statistical analyses were performed using the Statistical Package for Social Sciences for Windows ver 17.0 (SPSS Inc., Chicago, IL, USA). All categorical variables were reported as percentages and compared using chi-square test. Continuous variables were presented as mean \pm standard deviation (SD). Normality of variables was assessed by Kolmogorov-Smirnov test. Kruskal-Wallis test was conducted to compare parameters among groups and the Mann-Whitney $U$ test was performed to test the significance of pairwise differences for multiple comparisons. Pearson correlation coefficient test was used to assess the strength of association between MQSGA score and antropometric parameters. For all statistical tests, $p$ value of $<0.05$ was considered as statistically significant.

\section{RESULTS}

Our study included 55 geriatric patients 28 males and 27 females with the mean age of $72.9 \pm 8.4$ (range 65-79) years. The cause of renal failure among MHD patients included diabetic nephropaty, 17 (30.9\%); hypertension 22 (40.0\%), chronic glomerulonephritis, 3 (5.4\%), polycystic kidney disease, $3(5.4 \%)$, other $2(3.6 \%)$, and unknown in $8(14.6 \%)$ patients. The mean duration of HD was $30.36 \pm 15.70$ (range 3-63) months. Only three patients had central venous permanent catheters and the others $(n=52)$ had arteriovenous fistula. Based on the MQSGA score, 22 patients (40\%) were found to have adequate nutritional status, 20 patients (36.4\%) had mild-to-moderate malnutrition and 13 patients $(23.6 \%)$ had severe malnutrition. Demographic characteristics, baseline data, anthropometric measurements and laboratory parameters of study population are presented in Table 1 and Table 2.

All anthropometric measurements of patients with normal nutrition were significantly higher than patients with both mild-to-moderate and 


\begin{tabular}{|c|c|c|c|}
\hline Parameter & $\begin{array}{l}\text { Group I } \\
(n=22)\end{array}$ & $\begin{array}{l}\text { Group II } \\
(n=20)\end{array}$ & $\begin{array}{c}\text { Group III } \\
(n=13)\end{array}$ \\
\hline Age (year) & $68.9 \pm 3.4$ & $70.3 \pm 4.5$ & $78.6 \pm 3.6$ \\
\hline \multicolumn{4}{|l|}{ Gender } \\
\hline Female & 13 & 8 & 7 \\
\hline Male & 9 & 12 & 6 \\
\hline \multicolumn{4}{|l|}{ Comorbid conditions (\%) } \\
\hline Diabetes & 40.9 & 30.0 & 15.4 \\
\hline Hypertension & 36.4 & 25.0 & 46.1 \\
\hline Coronary arter disease & 18.2 & 25.0 & 30.8 \\
\hline Periferal vascular disease & - & 10 & 23 \\
\hline Literate (\%) & 59 & 55 & 23 \\
\hline Living with the family (\%) & 90.9 & 95 & 84.6 \\
\hline HD duration (month) & $32.8 \pm 13.6$ & $29.6 \pm 16.1$ & $28.2 \pm 11.8$ \\
\hline $\mathrm{Kt} / \mathrm{V}_{\text {urea }}$ & $1.4 \pm 0.1$ & $1.3 \pm 0.2$ & $1.3 \pm 0.1$ \\
\hline BMI $\left(\mathrm{kg} / \mathrm{m}^{2}\right)$ & $22.9 \pm 2.3$ & $21 \pm 1.6$ & $18.5 \pm 1.5$ \\
\hline
\end{tabular}

BMI: Body mass index; HD: Hypertension dialysis; MQSGA: Modified quantitative subjective global assessment.

severe malnutrition. Serum albumin, $\mathrm{Hb}$, total iron binding capacity, creatinin, phosphate levels were significantly lower in patients both mild-tomoderate and severe malnutrition. The MQSGA score had no significant correlation with gender $(p>0.05)$ and duration of HD ( $p>0.05)$, both men and women had equal tendency toward malnutrition. Additionally, if the sample was divided between those who had diabetes and those who did not, there was no significant correlation between diabetes and MQSGA score. When we assessed the correlation between MQSGA score and data in only malnourished patients $(n=33)$, a positive significant correlation was found between age $(\mathrm{r}=0.645, \mathrm{p}=0.000)$, CRP $(\mathrm{r}=0.239, \mathrm{p}=0.032)$, MIS $(r=0.612, p=0.000)$ and negative significant correlation was found between BMI $(r=-0.663$, $\mathrm{p}=0.000)$, BSF $(\mathrm{r}=-0.702, \mathrm{p}=0.000)$, TSF $(\mathrm{r}=$ $0.587, p=0.000), \operatorname{MAC}(r=-0.841, p=0.000)$, MAMC $(r=-0.830, p=0.000)$, phosphate $(r=-$ $0.324, p=0.014)$, albumin $(r=-0.519, p=0.011)$, $\mathrm{Hb}(\mathrm{r}=-0.439, \mathrm{p}=0.026)$ and total iron binding capacity $(r=-0.243, p=0.039)$ (Table 3$)$.

\section{DISCUSSION}

PEW is always underestimated and may lead to serious consequences in geriatric MHD patients, including impaired physical functioning, poorer quality of life, frequent superimposed illness and increased mortality [10]. KDOQI suggested that MHD patients should have periodic nutrition screening, consisting of laboratory measures (eg, albumin), body weight and food intake and repeated screening for malnutrition every six months [11].

The present study analyzed the prevalence of PEW defined according to MQSGA score and anthropometric measurements in elderly MHD patients. $60 \%$ of our elderly MHD patients had malnutrition $(36.4 \%$ of patients had at mild-tomoderate and $23.6 \%$ of patients had at severe level) and MQSGA score was elevated with patients' age. Even though, previous studies showed that malnutrition was significantly more frequent in women $[12,13]$, our study no significant correlation between malnutrition and gender. In elderly patients social isolation, cognitive dysfunction in maintain- 


\begin{tabular}{|c|c|c|c|c|}
\hline Parameter & $\begin{array}{l}\text { Group I } \\
(n=22)\end{array}$ & $\begin{array}{c}\text { Group II } \\
(n=20)\end{array}$ & $\begin{array}{c}\text { Group III } \\
(n=13)\end{array}$ & $\mathrm{p}$ value \\
\hline Hemoglobin $(\mathrm{g} / \mathrm{dl})$ & $11.6 \pm 0.4$ & $10.4 \pm 0.3$ & $9.2 \pm 0.6$ & $a, b, c$ \\
\hline Creatinine (mg/dl) & $9.6 \pm 2.7$ & $9 \pm 2.5$ & $7.8 \pm 1.7$ & $b, c$ \\
\hline Total cholesterol (mg/dl) & $184.6 \pm 52.3$ & $163.2 \pm 37.4$ & $140.1 \pm 23.9$ & $a, b, c$ \\
\hline Triglyceride (mg/dl) & $178.4 \pm 82.9$ & $155.1 \pm 41.9$ & $133.4 \pm 26.4$ & $a, b, c$ \\
\hline Albumin (g/dl) & $4 \pm 0.6$ & $3.5 \pm 0.8$ & $2.4 \pm 0.4$ & $a, b, c$ \\
\hline Phosphorus (mg/dl) & $4.9 \pm 1.2$ & $4.9 \pm 1$ & $3.2 \pm 0.9$ & $b, c$ \\
\hline Calcium (mg/dl) & $9 \pm 1.8$ & $9.2 \pm 1.9$ & $8.8 \pm 1.4$ & NS \\
\hline TIBC (mg/dl) & $189.2 \pm 43.4$ & $160.6 \pm 65.7$ & $141.9 \pm 32.1$ & $a, b, c$ \\
\hline PTH $(\mathrm{pg} / \mathrm{ml})$ & $346.3 \pm 72.9$ & $301.2 \pm 119.7$ & $215.3 \pm 62.2$ & $b, c$ \\
\hline CRP (mg/l) & $2.9 \pm 1.3$ & $3.8 \pm 1$ & $4.9 \pm 1.2$ & $b, c$ \\
\hline MQSGA & $8.1 \pm 1.6$ & $13.2 \pm 2.4$ & $22.8 \pm 2.8$ & $a, b, c$ \\
\hline MIS & $8.4 \pm 2.1$ & $12.2 \pm 1.4$ & $15.3 \pm 1$ & $a, b, c$ \\
\hline TSF (mm) & $11.9 \pm 2.1$ & $10.8 \pm 1.6$ & $8.9 \pm 1.1$ & $a, b, c$ \\
\hline $\mathrm{BSF}(\mathrm{mm})$ & $15.4 \pm 2$ & $13.4 \pm 1.8$ & $11 \pm 1$ & $a, b, c$ \\
\hline MAC (cm) & $27.3 \pm 1.6$ & $25.6 \pm 1$ & $22.5 \pm 1.2$ & $a, b, c$ \\
\hline MAMC $(\mathrm{cm})$ & $24 \pm 1.5$ & $22.2 \pm 1$ & $19.4 \pm 1$ & $a, b, c$ \\
\hline
\end{tabular}

BSF: Biceps skinfold; CRP: C-reactive protein; MAC: Mid-arm circumference; MAMC: Mid-arm muscle circumference; MIS: Malnutrition-inflammation score; MQSGA: Modified quantitative subjective global assessment; PTH: Parathyroid hormon; TIBC: Total iron binding capacity; TSF: Triceps skinfold; a: Comparison between group I and group II is $p<0.05$; b: Comparison between group II and group III is $p<0.05$; c: Comparison between group I and group III is $p<0.05$.

TABLE 3. The correlation analysis of anthropometric assessment and MQSGA in MHD patients with malnutrition

\begin{tabular}{lcc} 
Parameters & $\mathrm{r}$ & $\mathrm{p}$ \\
\hline BMI $\left(\mathrm{kg} / \mathrm{m}^{2}\right)$ & -0.663 & 0.000 \\
BSF $(\mathrm{mm})$ & -0.702 & 0.000 \\
TSF $(\mathrm{mm})$ & -0.587 & 0.000 \\
MAC $(\mathrm{cm})$ & -0.841 & 0.000 \\
MAMC $(\mathrm{cm})$ & -0.830 & 0.000
\end{tabular}

BMI: Body mass index; BSF: Biceps skinfold; MAC: Mid-arm circumference; MAMC: Mid-arm muscle circumference; TSF: Triceps skinfold.

ing basic nutritional requirements and depression may result in malnutrition. Furtermore, literacy state and living with family did not affect nutrition status in our patient groups.

Patients with DM have a higher incidence of PEW in comparison with non-DM in MHD pa- tients. Both insulin deprivation and degree of insulin resistance appear to play important role in this process $[14,15]$. In our study, there was no significant correlation with MQSGA score and DM in elderly MHD patients. We concluded that this is related with small number of diabetic malnurished elderly patients.

A serum cholesterol of $<100 \mathrm{mg} / \mathrm{dL}$ suggests the presence of protein-energy wasting among hemodialysis patients [16]. Although lower total cholesterol levels were observed in malnurished geriatric MHD patients, this study found no statically significant correlation between MQSGA scores and cholesterol levels $[17,18]$. Serum phosphorus levels were found low in elderly patients and this was considered as related with poor nutritional intake. When giving phosphorus binding threapy in elderly patients, it must be taken into account that this may lead lead to wasting, with loss of muscle mass and strength and ultimately worse physical functioning. A previous 
study showed that dose of dialysis was associated with improvement of nutritional status in MHD patients [19]. In our study, patient groups had a range of $\mathrm{Kt} /$ Vure between 1.3 and 1.6 and there was no marker for inadequate dialysis for malnutrition.

BMI and serum albumin levels have been traditionally known as nutritional markers. Many studies emphasize the protective effect of a higher BMI is in improved survival in MHD patients [20, 21]. Additionally, a BMI lower than $20 \mathrm{~kg} / \mathrm{m}^{2}$ is considered an index of malnutrition [22] and was found in the $48.5 \%$ of the malnourished patients.

In this study, we measured serum albumin levels to indirectly assess malnutrition and we found elderly malnourished MHD patients have significantly low albumin levels than well nourished patients. This may be due to lower protein intake, a lower rate of albumin synthesis or underlying inflammation among this population. Also, hypoalbuminemia has been the strongest predictor of cardiovascular disease and mortality in MHD patients [23,24]. Additionally, phycisians must keep in mind the specificity of serum albumin as a nutritional marker is limited in the presence of inflammation and fluid overload.

Inflammation is also an important factor affecting malnutrition and often co-exists in MHD patients. Meuwese et al. have reported that inflammation induced to increased lipolysis, muscle protein impairment, leading to sarcopenia, anorexia and increased mortality in these patients [25]. According to Kalantar-Zadeh et al study, CRP had significant correlation with MQSGA, similar to our finding [26]. Additionally, we showed that both serum CRP levels and MIS were significantly higher in malnourished elderly patients. The MIS was found significantly associated with hospitalization and mortality as well as indices of nutrition, inflammation and anemia $[27,28]$.

Malnutrition is a preventable and treatable condition, if it is identified earlier. The MAC reflects the thickness of subcutaneous fat and muscle and MAMC measures the protein status in the body. This study showed that anthropoemetric measurements (TSF, BSF, MAC and MAMC) had a significant negative correlation both MQSGA score and MIS in malnourished MHD patients. And these findings were similar to previous studies $[10,29]$ suggesting that decrease in anthropometric measurements is associated with increased malnutrition. Also, we found that anthropometric measurements had a significant positive correlation with BMI. According to our data, malnourished patients significantly have lower BMI than nonmalnourished patients. A meta-analysis reported the association of lower mortality rates in HD patients with higher BMI [30]. Combination of these anthropometric assessments may be as effective as MQSGA for evaluation of malnutrition of geriatric MHD patients and more frequent nutritional status evaluation in these patients may be more useful.

There are several limitations in this study. The small sample size may limit the power of the study. We did not analyze inflammatory markers (except CRP) to quantify the degree of systemic inflammation. Additionally, we did not use more elaborate methods, such as dual energy X-ray absorptiometry (DEXA) and bioelectrical impedance in this study. A large prospective study is needed to assesment of nutritional status and recommendations for prevention and treatment of malnutrition in elderly MHD patients.

In conclusion, malnutrition is very common and increasing with aging in geriatric MHD patients and physicians must be careful at early stage of malnutrition so as to increase the quality of life of these patients. MQSGA and antrophometric measurements may use to assess nutritional status in geriatric MHD patients.

\section{Conflict of Interest: None declared.}

Financial Disclosure: The authors declared that this study has received no financial support.

Authorship contributions: Concept - I.P.Y., R.U.; Design - I.P.Y., R.U; Supervision - I.P.Y., R.U., H.C., A.D.; Materials - I.P.Y., R.U.; Data collection \&/or processing - I.P.Y., R.U; Analysis and/or interpretation - I.P.Y., R.U.; Literature search - I.P.Y., R.U.; Writing - I.P.Y., R.U.; Critical review - H.C., A.D.

\section{REFERENCES}

1. Suleymanlar G, Ates K, Seyahi N. National Nephrology, Dialysis and Transplantation Registry Report of Turkey 2014. Ministry of Health and Turkish Society of Nephrology Joint Report, 
Ankara 2015.

2. Riella MC. Nutritional evaluation of patients receiving dialysis for the management of protein-energy wasting: what is old and what is new? J Ren Nutr 2013;23:195-8. Crossref

3. Dukkipati R, Kopple JD. Causes and prevention of proteinenergy wasting in chronic kidney failure. Semin Nephrol 2009;29:39-49. Crossref

4. Kim JC, Kalantar-Zadeh K, Kopple JD. Frailty and proteinenergy wasting in elderly patients with end stage kidney disease. J Am Soc Nephrol 2013;24:337-51. Crossref

5. Canaud B, Tong L, Tentori F, Akiba T, Karaboyas A, Gillespie B, et al. Clinical practices and outcomes in elderly hemodialysis patients: results from the Dialysis Outcomes and Practice Patterns Study (DOPPS). Clin J Am Soc Nephrol 2011;6:1651-62.

6. Santin FG, Bigogno FG, Dias Rodrigues JC, Cuppari L, Avesani CM. Concurrent and Predictive Validity of Composite Methods to Assess Nutritional Status in Older Adults on Hemodialysis. J Ren Nutr 2016;26:18-25. Crossref

7. Kalantar-Zadeh K, Ikizler TA, Block G, Avram MM, Kopple JD. Malnutrition-inflammation complex syndrome in dialysis patients: causes and consequences. Am J Kidney Dis 2003;42:864-81. Crossref

8. Mazairac AH, de Wit GA, Grooteman MP, Penne EL, van der Weerd NC, van den Dorpel MA, et al. A composite score of protein-energy nutritional status predicts mortality in haemodialysis patients no better than its individual components. Nephrol Dial Transplant 2011;26:1962-7. Crossref

9. Kalantar-Zadeh K, Kleiner M, Dunne E, Lee GH, Luft FC. A modified quantitative subjective global assessment of nutrition for dialysis patients. Nephrol Dial Transplant 1999;14:1732-8.

10. Chen J, Peng H, Yuan Z, Zhang K, Xiao L, Huang J, et al. Combination with anthropometric measurements and MQSGA to assess nutritional status in Chinese hemodialysis population. Int J Med Sci 2013;10:974-80. Crossref

11. K/DOQI, National Kidney Foundation. Clinical practice guidelines for nutrition in chronic renal failure. Am J Kidney Dis 2000;35:1-140.

12. Espahbodi F, Khoddad T, Esmaeili L. Evaluation of malnutrition and its association with biochemical parameters in patients with end stage renal disease undergoing hemodialysis using subjective global assessment. Nephrourol Mon 2014;6:16385. Crossref

13. Farrokhi R, Majdzadeh N, Dehghani M. Assessing Protein Intake through Urea Production Rate in Chronic Hemodialysis Patients of Kerman in 2001. J Kerman Univ Med Sci 2004;11:188-96.

14. Cano NJ, Roth H, Aparicio M, Azar R, Canaud B, Chauveau P, et al. Malnutrition in hemodialysis diabetic patients: evaluation and prognostic influence. Kidney Int 2002;62:593-601. Crossref

15. Pupim LB, Flakoll PJ, Majchrzak KM, Aftab Guy DL, Stenvinkel P, Ikizler TA. Increased muscle protein breakdown in chronic hemodialysis patients with type 2 diabetes mellitus. Kidney Int
2005;68:1857-65. Crossref

16. Fouque D, Pelletier S, Mafra D, Chauveau P. Nutrition and chronic kidney disease. Kidney Int 2011;80:348-57. Crossref

17. Basaleem HO, Alwan SM, Ahmed AA, Al-Sakkaf KA. Assessment of the nutritional status of end-stage renal disease patients on maintenance hemodialysis. Saudi J Kidney Dis Transpl 2004;15:455-62.

18. Zhang K, Cheng G, Cai X, Chen J, Jiang Y, Wang T, et al. Malnutrition, a new inducer for arterial calcification in hemodialysis patients? J Transl Med 2013;11:66. Crossref

19. Azar AT, Wahba K, Mohamed AS, Massoud WA. Association between dialysis dose improvement and nutritional status among hemodialysis patients. Am J Nephrol 2007;27:113-9. Crossref

20. Piccoli A, Nigrelli S, Caberlotto A, Bottazzo S, Rossi B, Pillon $\mathrm{L}$, et al. Bivariate normal values of the bioelectrical impedance vector in adult and elderly populations. Am J Clin Nutr 1995;61:269-70.

21. Kopple JD, Zhu X, Lew NL, Lowrie EG. Body weight-forheight relationships predict mortality in maintenance hemodialysis patients. Kidney Int 1999;56:1136-48. Crossref

22. Fouque D, Vennegoor M, ter Wee P, Wanner C, Basci A, Canaud B, et al. EBPG guideline on nutrition. Nephrol Dial Transplant 2007;22 Suppl 2:45-87. Crossref

23. Goodkin DA, Bragg-Gresham JL, Koenig KG, Wolfe RA, Akiba T, Andreucci VE, et al. Association of comorbid conditions and mortality in hemodialysis patients in Europe, Japan, and the United States: the Dialysis Outcomes and Practice Patterns Study (DOPPS). J Am Soc Nephrol 2003;14:3270-7. Crossref

24. Foley RN, Parfrey PS, Harnett JD, Kent GM, Murray DC, Barre PE. Hypoalbuminemia, cardiac morbidity, and mortality in end-stage renal disease. J Am Soc Nephrol 1996;7:728-36.

25. Meuwese CL, Carrero JJ, Stenvinkel P. Recent insights in inflammation-associated wasting in patients with chronic kidney disease. Contrib Nephrol 2011;171:120-6. Crossref

26. Kalantar-Zadeh K, Kopple JD, Block G, Humphreys MH. A malnutrition-inflammation score is correlated with morbidity and mortality in maintenance hemodialysis patients. Am J Kidney Dis 2001;38:1251-63. Crossref

27. Afşar B, Sezer S, Ozdemir FN, Celik H, Elsurer R, Haberal M. Malnutrition-inflammation score is a useful tool in peritoneal dialysis patients. Perit Dial Int 2006;26:705-11.

28. Kalantar-Zadeh K, Block G, McAllister CJ, Humphreys MH, Kopple JD. Appetite and inflammation, nutrition, anemia, and clinical outcome in hemodialysis patients. Am J Clin Nutr 2004;80:299-307.

29. Jones CH, Wolfenden RC, Wells LM. Is subjective global assessment a reliable measure of nutritional status in hemodialysis? J Ren Nutr 2004;14:26-30. Crossref

30. Jialin W, Yi Z, Weijie Y. Relationship between body mass index and mortality in hemodialysis patients: a meta-analysis. Nephron Clin Pract 2012;121:102-11. Crossref 